\title{
Guide for Technical Evaluation of Contractor Cost Proposals
}

May 1980

\section{U.S. Department of Energy}

Procurement and Contracts

Management Directorate

Office of Contract and Property

Management

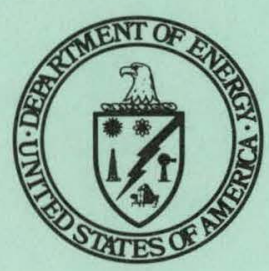




\section{DISCLAIMER}

This report was prepared as an account of work sponsored by an agency of the United States Government. Neither the United States Government nor any agency Thereof, nor any of their employees, makes any warranty, express or implied, or assumes any legal liability or responsibility for the accuracy, completeness, or usefulness of any information, apparatus, product, or process disclosed, or represents that its use would not infringe privately owned rights. Reference herein to any specific commercial product, process, or service by trade name, trademark, manufacturer, or otherwise does not necessarily constitute or imply its endorsement, recommendation, or favoring by the United States Government or any agency thereof. The views and opinions of authors expressed herein do not necessarily state or reflect those of the United States Government or any agency thereof. 


\section{DISCLAIMER}

Portions of this document may be illegible in electronic image products. Images are produced from the best available original document. 


\section{Guide for Technical Evaluation of Contractor Cost Proposals}

May 1980

\section{U.S. Department of Energy}

Procurement and Contracts

Management Directorate

Office of Contract and Property

Management

Washington, D.C. 20585

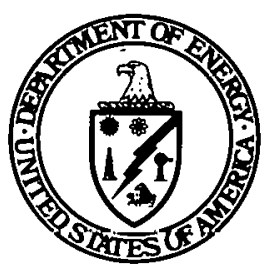




\section{Department of Energy \\ Washington, D.C. 20585}

Technical evaluation reports are needed to establish the reasonableness of the quantitative factors contained in the proposal (1abor hours and skill mix, types and quantities of material, computer and travel requirements, etc.). Where cost analysis is required pursuant to FPR 1-3.807-2(c), the overall reasonableness of the proposal cannot be established without an effective technical review of the quantitative factors included in the proposals.

GAO and other procurement review reports have indicated that, in many instances, technical evaluation reports were either not being provided to the contract specialist or, when provided, they were not adequate to establish the reasonableness of the quantitative factors included in the proposal.

To assist procurement and program offices in improving the quality of technical evaluation reports, we prepared the attached Technical Evaluation Guide. The document is a guide only and should be used accordingly. We have found, however, that this type of document, when used, has improved the quality of technical evaluation reports. Each activity is encouraged to use the gulde as a liaining aid, as wcll ao a reference source for technical evaluation reports.

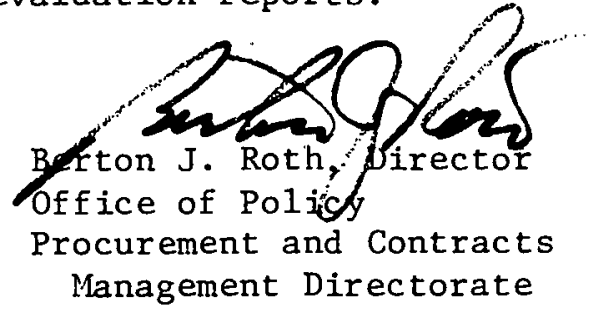

Attachment 
PURPOSE OF GUIDE

This guide explains the role of program office personnel as negotiation team members in the analysis of a contractor's cost proposal.

CONTENTS

Page

CHAPTER 1 - INTRODUCTION

CHAPTER 2 - THE PERFORMANCE OF TECHNICAL ' 2 EVALUATIONS

CHAPTER 3 - TECHNICAL EVALUATION REPORT

ATTACHMENTS

1. Checklist for Technical Evaluation of Proposals 5

2. Contractor's Proposal $\quad 8$

3. Summary Technical Evaluation Report 10

4. Detailed Technical Evaluation Report 11

5. Definitions 14

6. References 16 


\section{Chapter 1}

INTRODUCTION

1-1. Program Office technical personnel are a vital part of the Government!s negotiating team. Well-structured technical. evaluations of contractors' proposals that present information in a concise meaningful manner are a valuable tool for the support of contract negotiations. The technical review of the cost proposal is necessary: (a) to assist technical personnel in evaluating the offeror's understanding of technical requirements and the quality of the technical proposal, as well as (b) to assist the Contracting officer in establishing the reasonableness of the contract price.

1-2. Following is a quote from the Federal Procurement Regulation (FPR): "Some form of price or cost analysis is required with every negotiated procurement action." FPR, in implementing Public Law 87-653, The Truth in Negotiations Act, requires that cost analysis shall be performed whenever cost or pricing data is required. It is therefore necessary for the contractor to document the proposal with adequate cost substantiation data. The Government must also document the analysis of the contractor's data to support the negotiation objective and the negotiation results. This documentation is necessary to assure that a reasonable price is negotiated and that in the event the contractor's cost or pricing data was not accurate, current or complete, the Government has a documented basis for obtaining a contract price or cost and fee adjustment. 
1-3. Optional Form 60, Contract Pricing Proposal (Research and Development) is required to be used by contractors whenever cost or pricing data is required pursuant to FPR 1-3.807-3. The information furnished should include pertinent details as to cost elements for the specific statements, authorizations, and authentications required by the form.

1-4. The contracting officer is responsible for performing or having performed all administrative actions necessary for effective contracting. The contract pricing team to' support the contracting officer (FPR 1-801-3(b) (1) may include a price analyst, negotiator, buyer, project engineer, contract auditor (auditors are advisors to contracting officers on contractor accounting and contract audit matters, including such things as labor rates, overhead rates, incurred costs, and so forth) and other professional and technical specialists that may be required. 
Chapter 2

THE PERFORMANCE OF TECHNICAL EVALUATIONS

2-1. Technical evaluations of cost proposals are usually performed by program office personnel. They have a special interest in the procurement and likewise have an indepth technical understanding of the contract reqüirements.

2-2. Cost proposals are analyzed for the purpose of recommending to the Contracting Officer the reasonableness of the labor hours, material quantities, tooling, facilities, and other direct costs such as computer and travel. Technical evaluations should demonstrate that the proposal was given an adequate and objective evaluation, considering the complextty and the dollar value of the effort.

2-3. Technical evaluators should he familiar with and use the technique of performing a thorough review of representative portions of a complex proposal when time does not permit a detailed examination of the entire proposal. As you know, with an adequate sampling, the quality of the whole can be ascertained with a high-level of confidence. In fact, a higher level of confidence can be attained by utilizing limited resources in a thorough analysis of selected portions than will be attained by a cursory review of the total.

2-4. A checklist for technical evaluation of proposals (Attachment 1) is included as a guide to technical evaluations. (On major proposals a specific checklist should be developed to fit the particular procurement.) 


\section{Chapter 3}

TECHNICAL EVALUATION REPORT

3-1. Contractor cost proposals are complex documents, dividing cost estimates in three ways (1) cost element (for example, engineering labor hours, subcontracts); (2) tasks or Work Breakdown Structure (WBS), and (3) by time (for example, month, year). As such, Government personnel have a sizeable job in analyzing costs within the various levels of the matrix and maintaining an overall perspective of the procurement. It is therefore important that technical cost analysis reports be prepared by cost element with subbreakdowns by task and time, in order to summarize and price the results of the analysis parallel to the contractor's proposals.

3-2. Technical evaluation reports should contain (1) what was analyzed, (2) how it was analyzed, and (3) conclusions in sufficient detail to support preparation of the negotiation objective and the ensuing negotiation. This report must stand on its own as a record of the findings of the evaluation. It should be complete in itself. Opinions or conclusions voiced in the report without good justification are of little use to the contracting officer.

3-3. Contents of technical reports will vary according to the circumstances. Each program office should be encouraged to develop a standard format to fit its contracts and contractors. On major procurements it is important that the technical evaluation report be organized and tailored to the particular circumstances of the contract. 
3-4. A sample technical evaluation model consisting of (1) Contractor's Proposa1, (2) Summary Technical Evaluation Report, and (3) Detailed Technical Evaluation Report, is provided in Attachments 2 through 4. 
CHECKLIST FOR TECHNICAL EVALUATION OF PROPOSALS

1. Check to see that the work proposed covers minimum requirements and is responsive to the Work Statement and Specifications.

2. Check adequacy of documentation of and need for: Program Plans Quality Control Plans - Data Item Proposals - Make-or-Buy Information List of Proposed Tooling and Special Test Equipment (STE) - Listing of Proposed Spares - Materials Subcontracting Detail - Travel Detail, etc.

3. Check that the work breakdown structure was properly followed in the proposal and that a11 RFP items were proposed on.

4. Check proposed delivery schedules for conformance with program need dates.

5. Check overall efforts/materials and task-by-task efforts/materials against independent cost estimate (ICE) where available.

6. Check for items not required for Work Statement performance, or of no benefit to program.

7. Check capability and classification of direct personnel planned to be used on the job.

8. When contractor uses prior experience as basis of estimate, evaluate for degree of technical similarity (that is, complexity, size, etc.).

9. On follow-on procurements, eliminate nonrecurring effort by comparing prior work statements and specifications with current ones. Consider also degree of learning for the follow-on effort. 
10. Check reasonableness of labor loading and labor composition by task against milestone/time charts.

11. Check balancing of one type expense against another, that is, supervisory time versus workers' time, design against blueprint or model laboratory, etc. Also, check changes in balance as work progresses (less supervision, less design, more operational and reporting costs).

12. Check concurrency of labor and material usage by each type, i.e., fabrication labor requires raw material; assembly labor requires components, etc.

13. Where level of effort (for example; sustaining engineering) is required, have the contractor identify items to be produced to support quoted level of effort.

14. Check duplication of effort -- same work proposed under other tasks or other contracts.

15. Review contractor's evaluation of subcontractor's proposals.

16. Check that specifications do not restrict competition on initial subcontract source selection.

17. Where possible, are off-the-shelf type items being used by the prime contractor and subcontractors?

18. Check proposed material quantities against requirements for inplant usage and incorporation in deliverable end items. 
19. Check scrap factors, bad parts allowances, etc., against industry averages and/or against previous experience on similar work. (Try to find actuals; not negotiation records.)

20. Check the proposed travel by verifying destinations, length of stay, number of persons per trip, per diem, allowances, use of rental cars, etc.

21. Check other direct charges by questioning need, quantity, adequacy, possibility of a less expensive substitute, etc.

22. Check how bid 1abor amounts were developed -- consider Base hours + Fatigue + Delay + Personal.

(7) 
CONTRACTOR'S PROPOSAL *

Direct Engineering Labor

Design, testing and drafting hours:

Task 1 50U drawings (d $30 \mathrm{hrs}$ per drwg

Task 2200 drawings @ $30 \mathrm{hrs}$ per drwg

Task 390 drawings a $30 \mathrm{hrs}$ per drwg

15,000
6,000
2,700
Total: $\quad \frac{23,700}{23}$

Hours per class of engineer:

Engineer Task 1

Drafting $\quad 7,500$

Research
Total: $\quad \frac{3,000}{15,000}$

$4,500 \quad 1,800$

3,000

Task 3

Total

810

7,110 .

1,350

11,850

$\frac{1,200}{6,000}$

$\frac{540}{2,700}$

$\frac{4,740}{23,700}$

Explanation:

The number of direct engineering hours is based on the requirement for an estimated number of drawings for each task. Task 1 requirement is based on contract -0375 which required 600 drawings for a similar design. Based on the previous experience and a slightly less complex item, it is estimated that 16 percent less hours will be required. The data to verify the number of drawings for contract -0375 is in the files of the Engineering Department, Building 8A. Task 2 and 3 requirements are based on the actual drawings required for our commercial item Model A4J. It is estimated that the same number of drawings required on Model A4J will also be required on Tasks 2 and 3 . Mode1 A4J drawings dated between February and May $19 \times 4$ are located in the Engineering Department, Building 8A. The time required per drawing is the same as the average time experienced in 19x6. This can be identified by the cost summary figures in the cost ledger.

* Contractor proposals will be submitted on Optional Form 60, Contract Pricing Proposal. For illustration purposes and brevity, only the direct engineering labor portion of the contractor's. proposal is displayed. 
Direct engineering labor hour manload distribution was based on experience curves developed from prior programs.

$\begin{array}{lrrrrrrrrr} & \text { Jan } & \text { Feb } & \text { Mar } & \text { Apr } & \text { May } & \frac{\text { Jun }}{802} & \frac{\text { Jul }}{600} & \frac{\text { Aug }}{167} & \frac{\text { Total }}{7,110} \\ \text { Design } & 973 & 1,024 & 1,001 & 1,561 & 982 & 1,491 & 1,562 & 1,478 & 11,850 \\ \text { Drafting } & 1,400 & 1,503 & 1,575 & 1,625 & 1,216 & 1,492 \\ \text { Research } & 440 & 526 & 587 & 601 & 594 & 626 & 690 & 676 & 4,740\end{array}$


1. Contractor:

2. RFP/C.O. No.:

3. Description:

4. Cost Element:

5. Summary of Review:

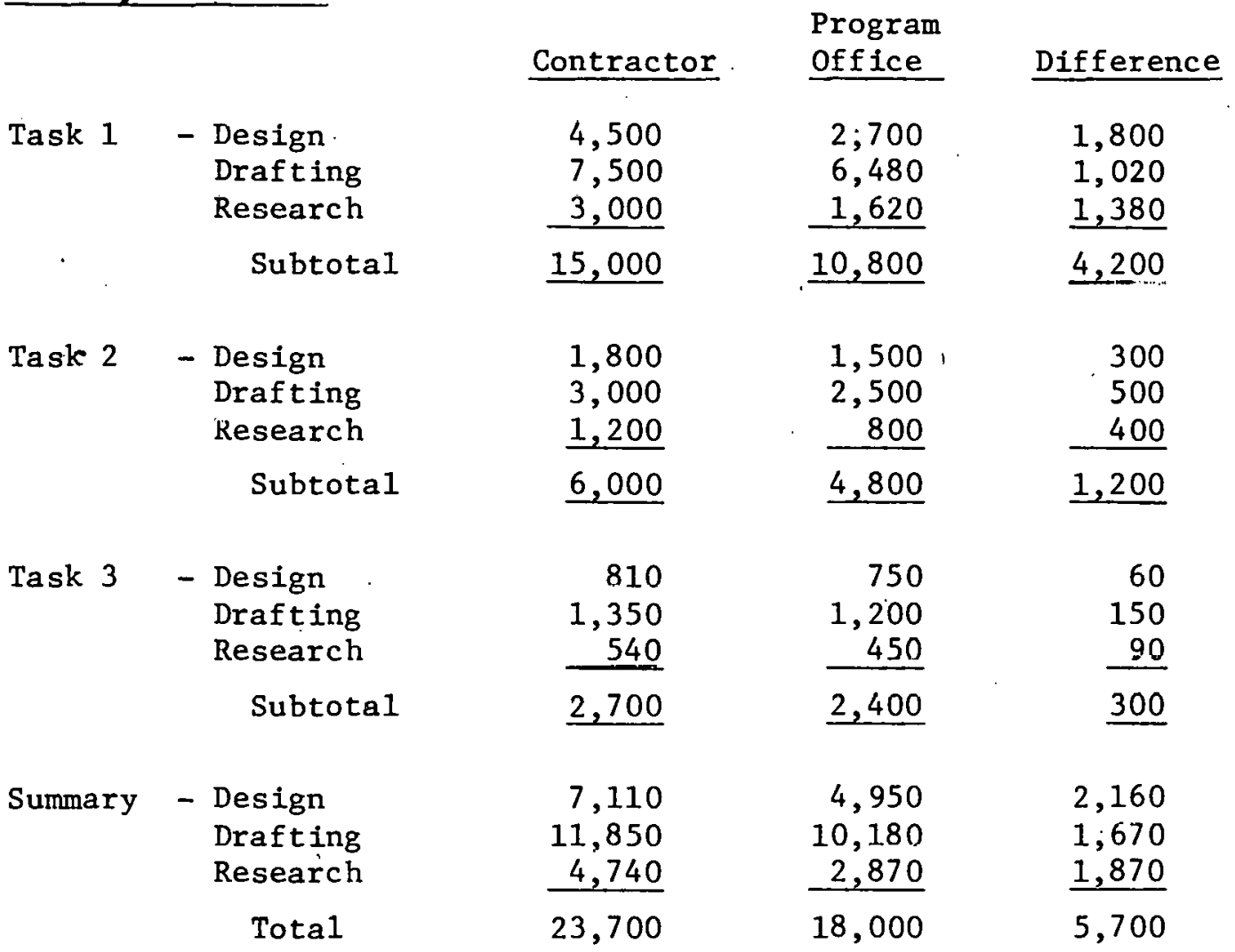

6. Contractor Manload: Distribution is considered acceptable. 
DETAILED TECHNICAL EVALUATION REPORT

1. Contractor: The Energy Company

2. RFP/C.O. No.:

3. Description: The 10 Program

4. Cost Element: Direct Engineering Labor Hours

5. Task Description: Task 1, Initial Design (NOTE)

6. Basis for Contractor's Estimate:

Contractor estimated the number of drawings based on experience of designing a similar item (contract $\mathrm{xxx}$ ) which required 600 initial design drawings. In addition, the contractor estimated that the current task will be 16 percent less complex (judgment) and therefore only 500 drawing hours will be used. The mix of labor was again based on a similar item, with design 30 percent, drafting 50 percent, and research 20 percent. Manloading was based on an estimating/budgeting guide developed by the contractor's engineering administration department which shows typical labor distribution curves. Average hours per drawing was based on experience in $19 \times 6$.

\section{Scope of Review:}

Selectively analyzed approximately 10 percent of the preliminary design layouts to determine the extent of initial design, changed design and common design that might be involved on the current procurement and relative complexity to the forerunner model. Made a. cursory review of the contractor's study of hours per drawing and manload curves. 


\section{Conclusions:}

Contractor's proposed work under this task is in accordance with the performance and schedule requirements of the RFP statement of work. Also, contractor's study showing an average of 30 hours for an initial drawing appears to be reasonable. Contractor's complexity factor of 16 percent is acceptable; however, it appears that the contractor will use a considerable number of drawings from the forerunner model with little or no change which should result in the following mix:

\begin{tabular}{|c|c|c|c|c|c|}
\hline Type of Drawing & $\begin{array}{c}\text { No. of } \\
\text { Drawings }\end{array}$ & & $\begin{array}{l}\text { Percent } \\
\text { of Initial }\end{array}$ & & $\begin{array}{c}\text { Equivalent } \\
\text { New Drawings } \\
\end{array}$ \\
\hline Initial & 250 & $\mathrm{X}$ & $100 \%$ & $=$ & 250 \\
\hline Changed & 150 & $\mathrm{X}$ & $60 \%$ & $=$ & 90 \\
\hline Common & 100 & $\mathrm{x}$ & $20 \%$ & $=$ & 20 \\
\hline Total Equivalent New & Drawings & & & & 360 \\
\hline Hours per drawing & & & & $\mathrm{X}$ & 30 \\
\hline Total hours & & & & & 10,800 \\
\hline
\end{tabular}

Due to the fact that 30 percent and 20 percent of the drawings will be changed design or common design, respectively (using forerunner model drawings), it is estimated that less design and research type labor will be required as follows:

\begin{tabular}{|c|c|c|c|c|c|}
\hline Category & $\begin{array}{l}\text { Program office } \\
\text { Estimated Mix }\end{array}$ & & $\begin{array}{l}\text { istimated } \\
\text { ota1 Hours }\end{array}$ & $\begin{array}{l}\text { Program office } \\
\text { :Position } \\
\end{array}$ & $\begin{array}{c}\text { Contractor's } \\
\text { Proposal } \\
\end{array}$ \\
\hline Design & $25 \%$ & $\mathrm{x}$ & 10,800 & $2,700 \mathrm{hrs}$ & 4,500 hrs \\
\hline Drafting & $60 \%$ & $\mathrm{x}$ & 10,800 & 6,480 & 7,500 \\
\hline Research. & $15 \%$ & $\mathrm{x}$ & 10,800 & 1,620 & 3,000 \\
\hline Total & & & & 10,800 hrs & $15,000 \mathrm{hrs}$ \\
\hline
\end{tabular}


9. Manloading: Contractor's manload distribution curves are acceptable in relation to the amount and scheduling of the task/design effort.

\section{Reviewed by: Name: \\ Date: \\ Symbol: \\ Extension:}

NOTE: For illustration purposes and brevity, detailed technical evaluation results are shown for Task 1 direct labor only. In actual practice, the technical evaluation report would cover all tasks as well as other elements of the proposal, such as materials, computer hours, travel, etc. 


\section{DEFINITIONS}

2-1. COST ANALYSIS - is the review and evaluation of a contractor's cost or pricing data and of the judgmental factors applied in projecting from the data to the estimated costs. Its purpose is to form an opinion on the degree to which the contractor's proposed costs represent what performance of the contrart should coct; aoouming reasoinable ecunumy and efficiency. It includes an evaluation of specific elements of costs and tasks [FPR 3-807.2(c)]

2-2. PRICE ANALYSIS - is the process of examining and evaluating a prospective price without evaluation of the separate cost elements and proposed profit. It includes the use of independent estimates, and of comparisons with like efforts.

2-3. TECHNICAL EVALUATION - a term used to describe proposal evaluation performed by engineers or other technical personnel. The technical evaluation (1) determines whether the contractor's proposed units of labor/material resources relate to the performance/schedule objectives of the contract, and (2) provides a quasi-cost analysis of the specific elements and tasks. Analysis by technical personnel includes a qualitative and quantitative evaluation of direct labor hours, materials, computer usage, travel (trips) and other direct charges where appropriate. Pricing rates and factors (that is, labor rates, overhead rates, computer rates, etc.) are analyzed by price analysts or auditors -- the auditors generally verifying data presented as current, complete and accurate, 
and the price analysts projecting verified and technical analyzed data into future time periods.

2-4. INDEPENDENT COST ESTIMATES - are developed by the Government for planning, budgeting, and proposal evaluation purposes. It is a form of price analysis, but normally is not a substitute for cost analysis unless prepared in sufficient detail that can be measured against contractor's estimates.

2-5. NEGOTIATION - is the process of discussing and agreeing on all terms and conditions of a proposed contract. Complete agreement of the parties on all basic issues, not necessarily each element of cost, shall be the objective of the contract negotiations.

2-6. RECORD OF NEGOTIATED PROCUREMENT ACTION (RNPA) - sets forth the principal elements of the price negotiation, for inclusion in the contract file and for the use of any reviewing authorities. RNPA includes reliance on or degree of reliance on contractor's cost or pricing data, development of negotiation objective, variance, and reasons therefore, between objective and the negotiated amounts, incentives and other related matters. Cost analysis reports from program office technical and field (for example, DCAA) personnel are used to support the RNPA. 
1. The following give the technical evaluator some sources of information, from a procurement point of view, that he should find useful in performing such an evaluation:

FPR 1-3.801-3(b)(5)(i)(1i) - Engineering appraisals and independent estimates by technical personncl as ways of assessing cost estimates. FPR 1-3.801-3(a) - Timely determination of requirements by personnel other than the contracting offices.

FPR 1-3.802(a) - Responsibility for adequacy of specifications and for delivery requirements.

FPR 1-3.803 - Type of contract.

FPR 1-3.807-3 - Requirements for cost or pricing data.

FPR 1-3.807-4 - Certificate of current cost or pricing data.

FPR 1-3.807-5 - Government rights to a price adjustment in case of defective cost or pricing data.

FPR 1-3.807-8 - Requires each contract to be priced independently, with no consideration given to previous losses or profits.

FPR 1-3.807-10 - Subcontracting considerations in cost analysis. FPR 1-3.807-11 - Overhead rate considerations. 
FPR 1-3.809 - Contract audit as a pricing aid.

FPR 1-3.811 - Requirement for Price Negotiation Memorandums

Armed Services Procurement Regulation Manual for Contract Pricing (ASPM No. 1) - Discusses the application of pricing policy to pricing problems. This is a DOD manual recently adopted by civil agencies for contract pricing covering contract types, incentives, profit, direct labor and materials, changes, spares, documentation, etc. Chapter 14 discusses the requirements for cost analysis reports, which are directly applicable to technical evaluation reports. 